\title{
Respiratory syncytial virus in preterm infants: 19 years of active epidemiological surveillance in a children's hospital
}

\author{
Ángela Gentile, M.D. ${ }^{a}$, María F. Lucion, M.D. ${ }^{a}$, María del Valle Juárez, M.D. ${ }^{a}$, \\ Vanesa Castellano, M.D. ${ }^{a}$, Julia Bakir, M.D. ${ }^{a}$, Anabella Pacchiotti, M.D. ${ }^{a}$, \\ María S. Areso, M.D. ${ }^{a}$, Mariana Viegas, M.D. ${ }^{b}$, Stephanie Goya, B.S. ${ }^{b}$ and \\ Alicia Mistchenko, M.D. ${ }^{b c}$
}

\begin{abstract}
Introduction. Respiratory syncytial virus (RSV) is the leading cause of acute lower respiratory tract infection (ALRTI) in pediatrics. Preterm infants are at a higher risk for complications. We aimed to describe and compare the clinical and epidemiological characteristics associated with ALRTI due to RSV in preterm and term infants and to establish the predictors of fatality among preterm infants.
\end{abstract}

Methods. Prospective, cross-sectional study of patients admitted due to ALRTI in the 2000-2018 period. Viral diagnosis was done by indirect immunofluorescence or reverse transcription polymerase chain reaction in nasopharyngeal aspirates. Clinical and epidemiological characteristics were recorded. A multiple logistic regression model established the predictors of fatality among preterm infants. Results. A total of 16018 ALRTI cases were included; $13545(84.6 \%)$ were tested; $6047(45 \%)$ were positive; RSV was prevalent in $81.1 \%$ (4907), with a seasonal epidemic pattern; $14 \%$ (686) were preterm infants.

Comorbidities, perinatal respiratory history, congenital heart disease, malnutrition, chronic respiratory disease, bronchopulmonary dysplasia, prior hospitalization due to ALRTI, and chronic neurological disease $(p<0.001)$ were more common among preterm infants; they required more intensive care and a longer length of stay, and had a higher fatality rate $(p<0.01)$. Congenital heart disease was an independent predictor of fatality due to RSV among preterm infants (OR: 3.67 [1.25-10.8], $p=0.01$ ).

Conclusion. RSV showed an epidemic pattern and affected more preterm infants with certain comorbidities, with a higher morbidity and mortality, compared to term infants. RSV fatality among preterm infants was associated with congenital heart disease.

Key words: respiratory tract infections, respiratory syncytialvirus, pretermnewborninfant, epidemiology.

María F. Lucion, M.D.: flor_lucion@yahoo.com

Funding:

None.

Conflict of interest: None.

Received: 12-2-2019

Accepted: 3-30-2020

To cite: Gentile Á, Lucion MF, Juárez MV, Castellano V, et al. Respiratory syncytial virus in preterm infants: 19 years of active epidemiological surveillance in a children's hospital. Arch Argent Pediatr 2020;118(6):386392.

\section{INTRODUCTION}

Acute lower respiratory tract infections (ALRTIs) in children are one of the most common reasons for medical consultation, school absenteeism, complications, and pediatric hospitalization. ${ }^{1,2}$ In Argentina, respiratory diseases are the third cause of mortality in children younger than 5 years of age, after perinatal conditions and congenital malformations. ${ }^{3,4}$

Respiratory syncytial virus (RSV) is the main cause of bronchiolitis and pneumonia among infants and children worldwide. ${ }^{4}$ On the one side, most previously healthy infants who experience an ALRTI due to RSV do not require hospitalization or, if they do, it is for a brief period of time (less than 5 days). ${ }^{2,5}$ On the other side, some pediatric populations have a high risk for severe RSV disease, such as preterm infants and those diagnosed with bronchopulmonary dysplasia, congenital heart disease with hemodynamic compromise, neuromuscular disease, and certain conditions involving immune deficiency. ${ }^{2,6-11}$

Hospitalization rates are high among children younger than 5 years old, but they are even higher among infants under 6 months and preterm infants under 1 year. ${ }^{12}$ So far, there is no available antiviral therapy or effective vaccine approved for its prevention.

The assessment of the risk for morbidity and mortality among preterm infants is considerably relevant for a timely decisionmaking in relation to prevention, early diagnosis, and adequate 
management actions. The objectives of this study were to describe and compare the clinical and epidemiological characteristics associated with ALRTI due to RSV in preterm and term infants and to establish the predictors of fatality among preterm infants with ALRTI due to RSV.

\section{MATERIAL AND METHODS Study design}

This was a prospective, analytical, and crosssectional study on ALRTI cases among patients hospitalized at a children's hospital.

\section{POPULATION}

Analyzed data were obtained as part of the active Epidemiological Surveillance Program (Programa de Vigilancia Epidemiológica, PVE) for ALRTI at Hospital de Niños Ricardo Gutiérrez (HNRG) in the 2000-2018 period. Data were collected prospectively in an epidemiological card of patients hospitalized in the clinical hospitalization ward and the intermediate and intensive care units of HNRG.

\section{Inclusion criteria}

All patients hospitalized due to ALRTI caused by community-acquired RSV between 2000 and 2018 in HNRG were included.

\section{Exclusion criteria}

Patients hospitalized for a different cause who developed an ALRTI during their length of stay were excluded.

\section{Clinical case definitions}

An ALRTI ${ }^{13}$ encompassed the following conditions:

- Bronchiolitis: first wheezing episode associated with clinical evidence of viral infection in children younger than 2 years. It referred to an acute and diffuse lower airway inflammation of infectious origin, with small airway obstruction as the main clinical characteristic.

- Pneumonia: acute infection of the lung parenchyma with clinical signs of invasion of the alveolar space.

Viral diagnosis was done by indirect immunofluorescence (IIF) or reverse transcription polymerase chain reaction ( $R T-P C R$ ) in nasopharyngeal aspirates obtained in the first 48 hours of admission. Samples were obtained using a K-30 nasogastric tube introduced through the nose and submitted immediately to the hospital's Laboratory of Virology. Preterm infant was defined as birth with a gestational age of less than 37 weeks.

\section{Sample size and selection}

Patients were included by consecutive sampling during the study period. A sample size of at least 10 events for each outcome measure was considered enough to be included in a multiple model.

\section{Data collection}

The following data were collected in the epidemiological card: date of admission, demographic data (age, sex, place of origin), clinical presentation (bronchiolitis, focal or multifocal pneumonia or pneumonia with effusion), prior hospitalizations related to a respiratory disease, readmission due to the same episode, comorbidities, perinatal history. Complications during hospitalization and clinical course (discharge, transfer to another facility, death), treatment, and length of stay. Comorbidities were defined as chronic or recurrent respiratory disease, malnutrition, congenital heart disease, genetic condition, neurological disease, and immunosuppression.

The presence of any of the following conditions was recorded as chronic or recurrent respiratory disease: recurrent obstructive bronchitis (ROB) or asthma, gastroesophageal reflux, pancreatic cystic fibrosis, bronchopulmonary dysplasia, recurrent pneumonia, and recurrent laryngitis. ROB was defined as the occurrence of two or more bronchial obstruction episodes.

As of 2012, the following data were also recorded: gestational age, birth weight, number of antenatal care visits, high-risk pregnancy, smoking during pregnancy, and second-hand smoking (World Health Organization's criterion).

\section{Seasonality}

RSV season onset and offset were estimated based on the description made in 2007 by Panozzo et al. ${ }^{14}$ Season onset was defined as the first of 2 consecutive weeks during which at least 2 samples tested positive for RSV and the percentage of samples testing positive was at least $10 \%$. Season offset was defined as the last of 2 consecutive weeks during which at least 2 samples tested positive and the percentage of samples testing positive was at least $10 \%$. Other viruses were described based on their distribution by epidemiological week. 


\section{Statistical analysis}

A general description was done in the first place by estimating the mean and standard deviation or the median and interquartile range (IQR) for numerical outcome measures, based on their distribution. The proportion and its corresponding $95 \%$ confidence interval (CI) were used for categorical outcome measures.

A simple logistic regression analysis was done to identify significant associations between the occurrence of ALRTI by RSV among preterm and term infants. A multiple logistic regression model was developed to identify predictor outcome measures of fatality among preterm infants hospitalized due to ALRTI by RSV.

Outcome measures significantly associated in the analysis of crude data $(p<0.2)$ and / or those considered clinically relevant were added one at a time; only those showing a significant association with fatality (Wald test) were maintained in the final model. The STATA/SE software, version 13, was used for statistical analysis. The odds ratio (OR) with a $95 \% \mathrm{CI}$ was used as a measure of association. The study was approved by both the Ethics and Research Committees of HNRG.

\section{RESULTS \\ General description of the population}

In the 19-year study period, a total of 16018 patients were admitted due to community-acquired ALRTI; of them, $13545(85 \%)$ were tested for respiratory viruses and $6047(45 \%)$ had a positive result (Figure 1). RSV was the most prevalent virus across the study period ( $81.1 \%, 4907$ patients). Figure 1 shows the flowchart of case inclusion and viral rescue. The clinical characteristics of preterm infants are described in Table 1, including gestational age, birth weight, and perinatal history as of 2012.

\section{Seasonality}

The cases of ALRTI due to RSV showed a seasonal epidemic pattern consistent with the months of higher relative humidity and lower mean temperature values: May through July (Figure 2).

\section{Clinical and epidemiological characteristics of the study population}

In the total population included in this study, there was a slight predominance of boys (56.5\%),

FIGURE 1. Flowchart of the population of cases with acute lower respiratory tract infection and viral rescue

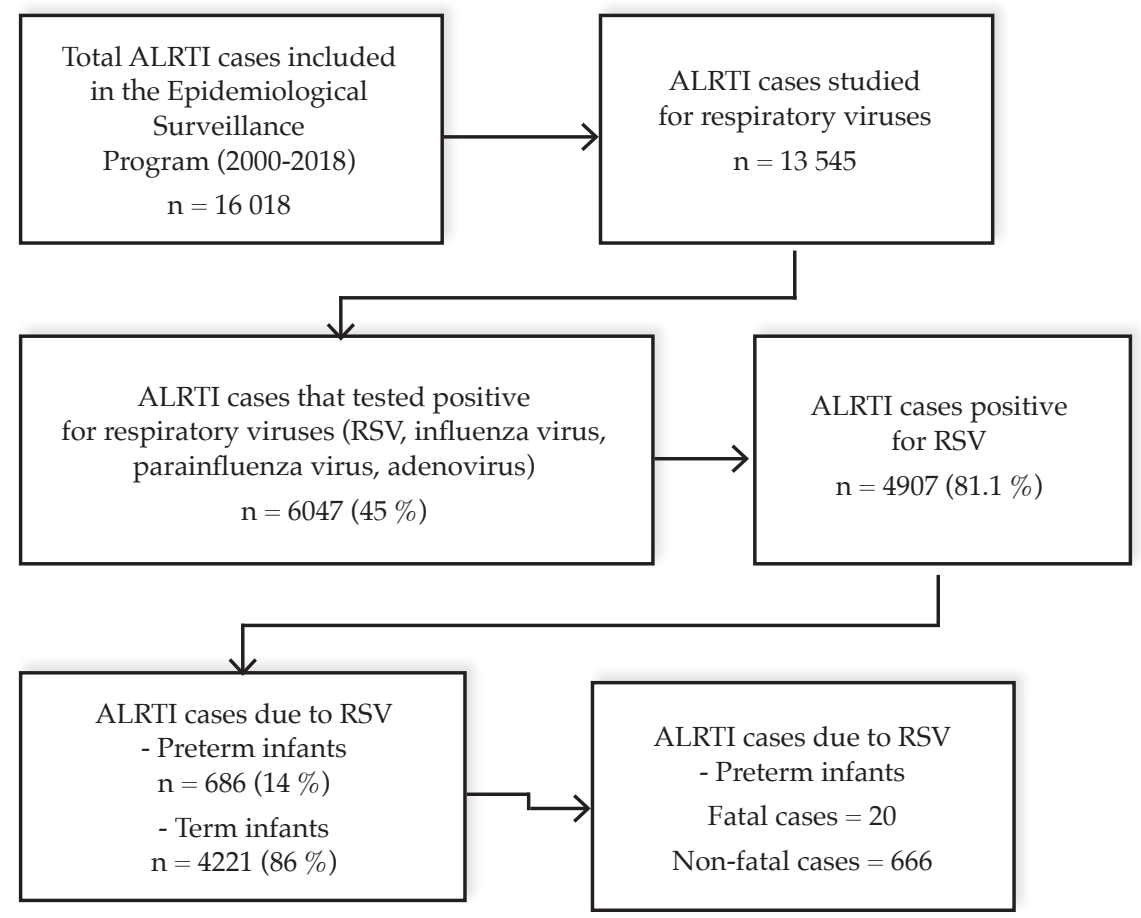

ALRTI: acute lower respiratory tract infection; RSV: respiratory syncytial virus. 
and median age was 7 months (IQR: 2-12); almost two-thirds were infants under 12 months, and $42 \%$ were younger than 6 months. In addition, $14 \%(686 / 4907)$ were preterm infants.

Table 2 describes the clinical and epidemiological characteristics of the study population in detail and compares preterm and term infants. In terms of complications during the stay at the hospital, these were more common among preterm infants. Table 3 describes the comparison of clinical course during hospitalization, complications, and fatality between preterm and term infants.

The distribution of the different clinical and epidemiological characteristics of preterm infants with ALRTI due to RSV is described in
Table 4, comparing fatal and non-fatal cases. The multivariate analysis showed that congenital heart disease was the only independent predictor of fatality due to RSV among preterm infants (OR: 3.67; $95 \%$ CI: 1.25-10.78; $p=0.017$ ).

\section{DISCUSSION}

This study describes the characteristics of preterm infants hospitalized systematically due to ALRTI by RSV at a children's hospital for the duration of 18 seasons. Throughout the study period, RSV was the most commonly isolated infectious agent, without significant annual variations. The most frequently affected age group corresponded to infants under 1 year. These results were consistent with those of

TABLE 1. Clinical characteristics of preterm infants

\begin{tabular}{lc}
\hline $\mathbf{n}=\mathbf{1 6 6}$ & $\%$ \\
\hline$<28$ weeks (extremely preterm infants) & 6.63 \\
28-32 weeks (very preterm infants) & 27.7 \\
32.1-36.6 weeks (moderate to late preterm infants) & 65.66 \\
Birth weight in grams (median, IQR) & $2030(1500-2500)$ \\
Antenatal care visits ( $\geq 3)$ & 93.3 \\
High-risk pregnancy & 38.8 \\
Breastfeeding (currently or up to 6 months old) & 35.2 \\
Smoking during pregnancy & 11.2 \\
Second-hand smoking & 32.4 \\
\hline
\end{tabular}

IQR: interquartile range.

FIGURE 2. Seasonal epidemic pattern of acute lower respiratory tract infection cases caused by respiratory syncytial virus. 2000-2018

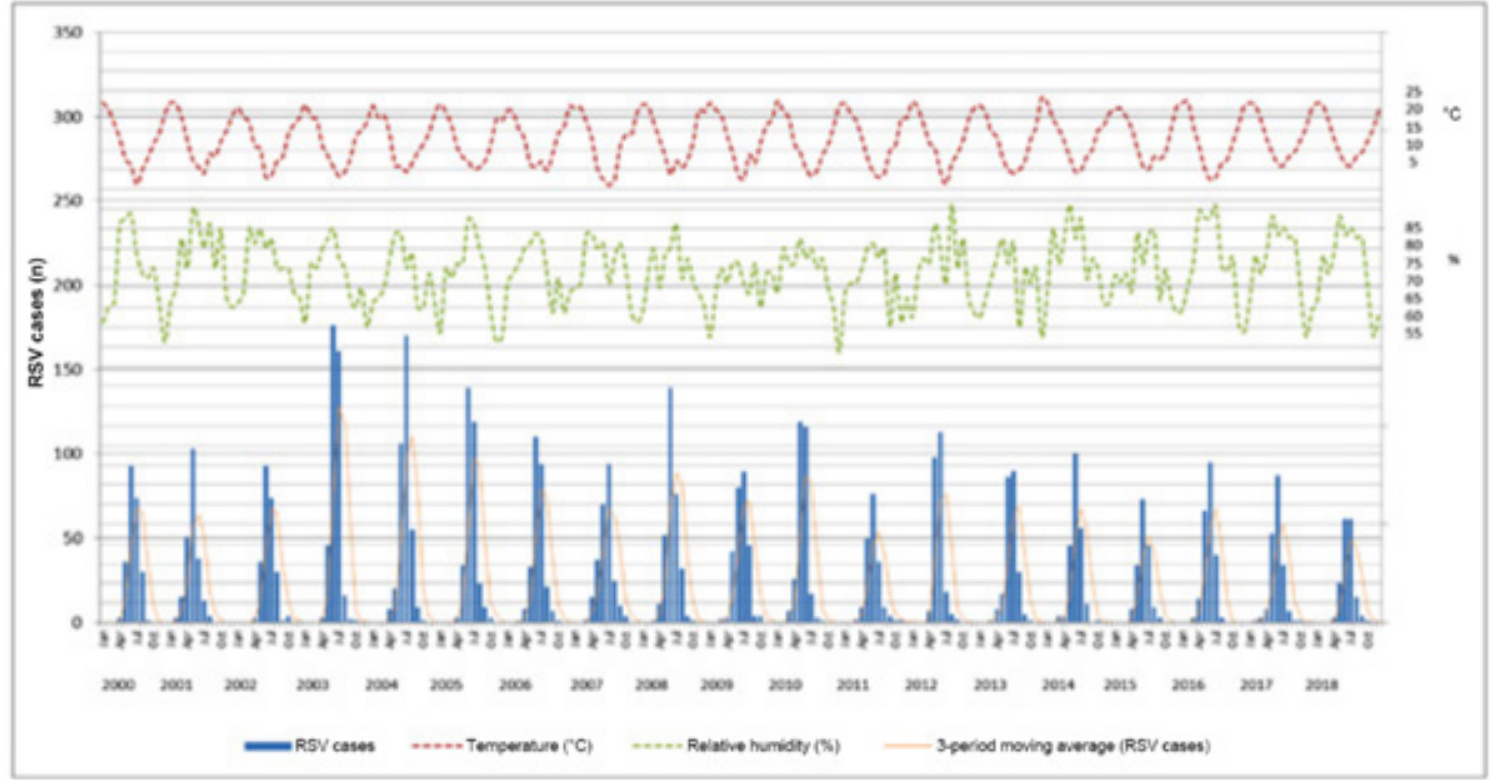

ALRTI: acute lower respiratory tract infection; RSV: respiratory syncytial virus. 
different epidemiological studies done in our region. ${ }^{15,16}$

RSV circulation showed the usual seasonal epidemic pattern observed in temperate climate regions. Viral circulation onset and offset corresponded to epidemiological weeks 18 and 33, respectively, consistent with the months of higher relative humidity and lower mean temperature values in Buenos Aires (May-July). ${ }^{17-20}$ Among RSV patients, $14 \%$ had been born prematurely, similar to what has been described in other studies. ${ }^{7,15,18,21}$

Compared to term infants, preterm infants with RSV infection more commonly

TABLE 2. Clinical and epidemiological characteristics of cases of acute lower respiratory tract infection due to respiratory syncytial virus admitted to the Epidemiological Surveillance Program between 2012 and 2018 comparing preterm and term infants

\begin{tabular}{|c|c|c|c|c|c|}
\hline Characteristics & $\begin{array}{l}\text { Preterm } \\
(n=686)\end{array}$ & $\begin{array}{c}\text { Term } \\
(\mathrm{n}=4221)\end{array}$ & OR & $95 \% \mathrm{CI}$ & $p$ \\
\hline Sex (male) & $58.2 \%$ & $56.1 \%$ & 1.1 & $0.9-1.3$ & 0.28 \\
\hline Chronological age, months old (median) & $7(4-13)$ & $7(3-12)$ & 0.22 & & \\
\hline Bronchiolitis & $60.7 \%$ & $61.6 \%$ & 0.9 & $0.8-1.1$ & 0.65 \\
\hline Comorbidities & $56.3 \%$ & $38.6 \%$ & 2.1 & $1.7-2.4$ & $<0.001$ \\
\hline Perinatal respiratory history & $46.7 \%$ & $5.4 \%$ & 15.3 & $12.6-18.8$ & $<0.001$ \\
\hline Congenital heart disease & $8.4 \%$ & $5.7 \%$ & 1.5 & $1.1-2.0$ & 0.005 \\
\hline Malnutrition & $9.9 \%$ & $3.7 \%$ & 2.8 & $2.1-3.8$ & $<0.001$ \\
\hline Chronic respiratory disease & $41.5 \%$ & $28.9 \%$ & 1.7 & $1.5-2.1$ & $<0.001$ \\
\hline Bronchopulmonary dysplasia & $7 \%$ & $0.07 \%$ & 98.7 & $32.2-401$ & $<0.001$ \\
\hline Immunosuppression & $1 \%$ & $2.1 \%$ & 0.5 & $0.2-1.1$ & 0.06 \\
\hline Chronic neurological disease & $7.4 \%$ & $3.6 \%$ & 2.1 & $1.5-2.9$ & $<0.001$ \\
\hline Prior hospitalization due to ALRTI & $42.6 \%$ & $24 \%$ & 2.3 & $1.9-2.7$ & $<0.001$ \\
\hline Readmission & $4.8 \%$ & $3.1 \%$ & 1.6 & $1.1-2.3$ & 0.02 \\
\hline
\end{tabular}

ALRTI: acute lower respiratory tract infection; OR: odds ratio; CI: confidence interval.

TABLE 3. Clinical course during hospitalization, complications, and fatality among cases of acute lower respiratory tract infection due to respiratory syncytial virus admitted to the Epidemiological Surveillance Program between 2012 and 2018 comparing preterm and term infants

\begin{tabular}{|c|c|c|c|c|c|}
\hline Course & $\begin{array}{l}\text { Preterm } \\
(\mathrm{n}=686)\end{array}$ & $\begin{array}{c}\text { Term } \\
(\mathrm{n}=4221)\end{array}$ & OR & $95 \% \mathrm{CI}$ & $p$ \\
\hline Length of stay, days (median, IQR) & $8(5-11)$ & $7(5-10)$ & & & $<0.001$ \\
\hline Intensive care requirements & $11 \%$ & $7.7 \%$ & 1.5 & $1.14-1.95$ & 0.003 \\
\hline Health care-associated infection & $7.9 \%$ & $6.0 \%$ & 1.3 & $0.98-1.8$ & 0.078 \\
\hline Fatality rate & $2.9 \%$ & $1.5 \%$ & 2.0 & $1.18-3.28$ & 0.012 \\
\hline
\end{tabular}

OR: odds ratio; CI: confidence interval; IQR: interquartile range.

TABLE 4. Clinical and epidemiological characteristics, complications, and fatality among preterm infants with acute lower respiratory tract infection due to respiratory syncytial virus admitted to the Epidemiological Surveillance Program between 2012 and 2018 comparing fatal and non-fatal cases

\begin{tabular}{|c|c|c|c|c|c|c|}
\hline \multirow[b]{2}{*}{ Sex (male) } & \multirow{2}{*}{$\begin{array}{c}\begin{array}{c}\text { Fatal cases } \\
(\mathbf{n}=\mathbf{2 0})\end{array} \\
50 \%\end{array}$} & \multirow{2}{*}{$\begin{array}{c}\begin{array}{c}\text { Non-fatal cases } \\
(\mathbf{n}=666)\end{array} \\
58.3 \%\end{array}$} & \multirow{2}{*}{$\begin{array}{c}\text { OR } \\
1.4\end{array}$} & \multicolumn{2}{|c|}{$95 \%$ CI } & \multirow{2}{*}{$\begin{array}{c}p \\
0.607\end{array}$} \\
\hline & & & & 0.57 & 3.40 & \\
\hline Chronological age, months old (median) & $4(2-7.5)$ & $8(4-14)$ & & & & 0.290 \\
\hline Bronchiolitis & $45 \%$ & $61 \%$ & 0.52 & 0.21 & 1.27 & 0.224 \\
\hline Comorbidities & $60 \%$ & $56.3 \%$ & 1.16 & 0.46 & 3.02 & 0.920 \\
\hline Perinatal respiratory history & $70 \%$ & $46 \%$ & 2.71 & 1.03 & 7.15 & 0.061 \\
\hline Congenital heart disease & $25 \%$ & $8 \%$ & 3.81 & 1.33 & 10.91 & 0.023 \\
\hline Malnutrition & $25 \%$ & $9.4 \%$ & 3.2 & 1.13 & 9.22 & 0.052 \\
\hline Chronic respiratory disease & $35 \%$ & $41.9 \%$ & 0.74 & 0.29 & 1.89 & 0.694 \\
\hline Bronchopulmonary dysplasia & $5 \%$ & $5.9 \%$ & 0.84 & 0.10 & 6.45 & 0.860 \\
\hline Prior hospitalization due to ALRTI & $50 \%$ & $42.5 \%$ & 1.35 & 0.55 & 3.29 & 0.660 \\
\hline Chronic neurological disease & $10 \%$ & $7.27 \%$ & 1.4 & 0.31 & 6.28 & 0.979 \\
\hline
\end{tabular}

OR: odds ratio; CI: confidence interval; ALRTI: acute lower respiratory tract infection. 
had underlying conditions, including neonatal respiratory disease, bronchopulmonary dysplasia, congenital heart disease, malnutrition, and chronic neurological disease, prior hospitalizations due to respiratory conditions, and were more frequently readmitted..$^{2,5-8,22}$ In addition, they showed a more severe profile and required intensive care and a longer length of stay, as described in the bibliography. ${ }^{23-25}$ In our series, the fatality rate doubled compared to term infants.

Several studies assessed gestational age and other socio-environmental factors as determinants of disease severity in the first year of life. ${ }^{12,19,26}$ Unfortunately, as gestational age was not recorded for the complete series, this outcome measure was not included in the analysis. However, it is worth noting that our population corresponded most to moderate to late preterm infants and showed a high level of adherence to antenatal care visits, a low rate of breastfeeding, and a significant percentage of second-hand smoking.

One of the strengths of this study is its methodological design, a prospective active surveillance based on robust epidemiological data, a large enough sample that allows to draw robust statistical conclusions, and individual patient data. In addition, the recommendation is to use IIF for the rapid detection and diagnosis of respiratory viruses as the screening method in the pediatric population. This is a broadly used method because it is a simple, quick, low-cost technique with high sensitivity and specificity to detect the viruses that usually cause ALRTI. ${ }^{27-30}$

A limitation of this study was that it was done in a single site, a tertiary care hospital, so the complexity of included patients makes it hard to extrapolate the results to the general population. The high proportion of comorbidities in these patients may overestimate RSV symptoms and severity when complications are analyzed. Therefore, considering that this is a hospital-based study, it is not possible to infer results in the general population because it is not representative of it. In this study, only the presence of heart disease was associated with fatality among preterm infants according to the multivariate analysis; however, these results may differ from those of large-scale studies or those with a higher number of events.

The only available method of prophylaxis against RSV is palivizumab, which is useful to prevent severe RSV disease among extremely preterm infants or those with congenital heart disease or chronic obstructive pulmonary disease. ${ }^{6}$ Approximately 60 strategies are being developed between vaccines and RSV humanized monoclonal antibodies; of these, 16 are being investigated in phase 1-3 trials. ${ }^{31,32}$

\section{CONCLUSIONS}

To conclude, RSV showed a seasonal epidemic pattern (May-July) and affected preterm infants with certain comorbidities, leading to a more severe condition, more complications, and a higher fatality rate than in term infants. RSV fatality among preterm infants was associated with congenital heart disease.

These epidemiological data, together with ongoing global studies, will be crucial to work on the prevention of RSV infection with specific vaccines, optimize immunization schedules and age groups, and then assess their effectiveness and, thus, tighten health policies.

\section{REFERENCES}

1. Sociedad Argentina de Pediatría. Comité de Infectología Pediátrica.Sincicial Respiratorio. In:Libro Azul de Infectología Pediátrica. $4^{\text {th }}$ ed. Buenos Aires: FUNDASAP; 2012.Pages 413-7.

2. American Academy of Pediatrics. Respiratory Syncytial Virus. In: Kimberlin DW, Brady MT, Jackson MA, Long SS, eds. Red Book: 2018 Report of the Committee on Infectious Diseases. $31^{\text {st }}$ ed. Itasca, IL: American Academy of Pediatrics; 2018.Pages 682-92.

3. Dirección de Estadísticas e Información de Salud. Información Básica, año 2017. Estadísticas Vitales Serie 5, No 61. Buenos Aires: Ministerio de Salud de la Nación; 2019. [Accessed on: March 30 $\left.0^{\text {th }}, 2020\right]$. Available at: http: / / www.deis.msal.gov.ar/wp-content/uploads / 2019/01/ Serie5Nro61.pdf.

4. Shi T, McAllister DA, O'Brien KL, Simoes EAF, et al. Global, regional, and national disease burden estimates of acute lower respiratory infections due to respiratory syncytial virus in young children in 2015: a systematic review and modelling study. Lancet. 2017; 390(10098):946-58.

5. Sommer C, Resch B, Simoes EA. Risk factors for severe respiratory syncytial virus lower respiratory tract infection. Open Microbiol J. 2011; 5:144-54.

6. Fernández Jonusas S, Albas Maubett D, Satragno D, Adriana Cattaino, et al. Recomendaciones sobre el uso de palivizumab. Actualización 2015. Arch Argent Pediatr. 2016; 114(1):84-8.

7. García CG, Bhore R, Soriano Fallas A, Trost M, et al. Risk factorsin children hospitalized with RSV bronchiolitis versus non-RSV bronchiolitis. Pediatrics. 2010; 126(6):e1453-60.

8. Andres S, Bauer G, Rodríguez S, Novali L, et al. Hospitalization due to respiratory syncytial virus infection in patients under 2 years of age with hemodynamically significant congenital heart disease. J Pediatr (Rio J). 2012; 88(3):246-52.

9. Wilkesmann A, Ammann RA, Schildgen O, Eis-Hübinger $\mathrm{AM}$, et al. Hospitalized children with respiratory syncytial virus infection and neuromuscular impairment face an increased risk of a complicated course. Pediatr Infect Dis J. 2007; 26(6):485-91. 
10. Gentile A, Lucion MF, Juarez MDV, Areso MS, etal. Burden of Respiratory Syncytial Virus Disease and Mortality Risk Factors in Argentina: 18 Years of Active Surveillance in a Children's Hospital. Pediatr Infect Dis J. 2019; 38(6):589-94.

11. Fauroux B, Simões EAF, Checchia PA, Paes B, et al. The Burden and Long-term Respiratory Morbidity Associated with Respiratory Syncytial Virus Infection in Early Childhood. Infect Dis Ther. 2017; 6(2):173-97.

12. Stein RT, BontLJ,ZarH, PolackFP, etal. Respiratory syncytial virus hospitalization and mortality: Systematic review and meta-analysis. Pediatr Pulmonol. 2017; 52(4):556-69.

13. Ministerio de Salud del GCBA. Gerencia Operativa de Epidemiologia. Dirección General de Informática Clínica, Estadística y Epidemiología. Subsecretaría de Planificación Sanitaria. Actualización en vigilancia de infecciones respiratorias agudas 2017, CABA. Memo 9 de Junio 2017. [Accessed on: March 30 $\left.{ }^{\text {th }}, 2020\right]$. Available at: https: / / www. buenosaires.gob.ar/sites/gcaba/files/memorespiratorias_ actualizacion_20170609.pdf.

14. Panozzo CA, Fowlkes AL, Anderson LJ. Variation in timing of respiratory syncytial virus outbreaks:lessonsfromnational surveillance. Pediatr Infect Dis J. 2007; 26(11 Suppl):S41-5.

15. Piñeros JG, Baquero H, Bastidas J, García J, et al. Respiratory syncytial virus infection as a cause of hospitalization in population under 1 year in Colombia. J Pediatr (Rio J). 2013; 89(6):544-8.

16. Gamiño-Arroyo AE, Moreno-Espinosa S, LlamosasGallardo B, Ortiz-Hernández AA, et al. Epidemiology and clinical characteristics of respiratory syncytial virusinfections among children and adults in Mexico. Influenza Other Respir Viruses. 2017; 11(1):48-56.

17. Gurgel RQ, Bezerra PG, Duarte Mdo C, Moura AÁ, et al. Relative frequency, Possible Risk Factors, Viral Codetection Rates, and Seasonality of Respiratory Syncytial Virus Among Children With Lower Respiratory Tract Infection in Northeastern Brazil. Medicine (Baltimore). 2016;95(15):e3090.

18. Kamigaki T, Chaw L, Tan AG, Tamaki R, et al. Seasonality of Influenza and Respiratory Syncytial Viruses and the Effect of Climate Factors in Subtropical-Tropical Asia Using Influenza-Like Illness Surveillance Data, 2010-2012. PLoS One. 2016; 11(12):e0167712.

19. Viegas M, Barrero PR, Maffey AF, Mistchenko AS. Respiratory viruses seasonality in children under five years of age in Buenos Aires, Argentina: a five-year analysis. J Infect. 2004; 49(3):222-8.

20. Lucion MF, Juárez MV, Viegas M, Castellano V, et al. Virus respiratorio sincicial. Patrón clínico epidemiológico en niños internados en un hospital pediátrico durante los años 2000-2013. Arch Argent Pediatr. 2014; 112(5):397-404.

21. Resch B, Gusenleitner W, Müller W. The impact of respiratory syncytial virus infection: a prospective study in hospitalized infants younger than 2 years. Infection. 2002; 30(4):193-7.

22. Sheridan $\square$ Pereira M, Murphy J, Sloan J, Crispino G, et al. Respiratory syncytial virus preterm (32 $\square 36$ completed weeks of gestation) risk estimation measure for RSV hospitalization in Ireland: a prospective study. Pediatr Infect Dis J. 2016; 35(1):19-24.

23. Hall CB, Weinberg GA, Iwane MK, Blumkin AK, et al. The burden of respiratory syncytial virus infection in young children. N Engl J Med. 2009; 360(6):588-98.

24. Hall CB, Weinberg GA, Blumkin AK, Edwards KM, et al. Respiratory syncytial virus-associated hospitalizations among children less than 24 months of age. Pediatrics. 2013; 132(2):e341-8.

25. McLaurin KK, Farr AM, Wade SW, Diakun DR, et al. Respiratory syncytial virus hospitalization outcomes and costs of full-term and preterm infants. J Perinatol. 2016;36(11):990-6.

26. StraňákZ, SalibaE, KosmaP, Posfay-BarbeK, etal. Predictors of RSV LRTIHospitalization in Infants Born at 33 to 35 Weeks Gestational Age: A Large Multinational Study (PONI). PLoS One. 2016; 11(6): $\mathrm{e} 0157446$.

27. Sadeghi C, Aebi C, Gorgievski-Hrisoho M, Mühlemann $\mathrm{K}$, et al. Twelve years detection of respiratory viruses by immunofluorescence in hospitalized children: impact of the introduction of a new respiratory picornavirus assay. BMC Infect Dis. 2011; 11:41.

28. Portillo C, Cruz J. Implementación del método rápido de diagnóstico de virus por inmunofluorescencia en niños hospitalizados por infecciones respiratorias agudas. Arch Argent Pediatr. 2000; 98(2):99-102.

29. Griffin MR, Walker FJ, Iwane MK, Weinberg GA, et al. Epidemiology of respiratory infections in young children: insights from the new vaccine surveillance network. Pediatr Infect Dis J. 2004; 23(11 Suppl):S188-92.

30. Nair H, Nokes DJ, Gessner BD, Dherani M, et al. Global burden of acute lower respiratory infections due to respiratory syncytial virus in young children: a systematic review and meta-analysis. Lancet. 2010;375(9725):1545-55.

31. Anderson LJ. Respiratory syncytial virus vaccine development. Semin Immunol. 2013; 25(2):160-71.

32. Lucion MF, Viegas M, Gentile A. VSR: un futuro promisorio en vacunas. Rev Hosp Niños (B. Aires). 2018; 60(268):118-24. 